\title{
An Evaluation of the Nonlinearity Correction Applied to Atmospheric Emitted Radiance Interferometer (AERI) Data Collected by the Atmospheric Radiation Measurement Program
}

September 2004

D.D. Turner, H.E. Revercomb,

R.O. Knuteson, R.G. Dedecker, and W.F. Feltz

Work supported by the U.S. Department of Energy, Office of Science, Office of Biological and Environmental Research 


\section{Contents}

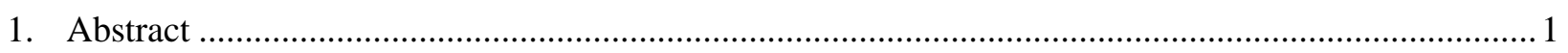

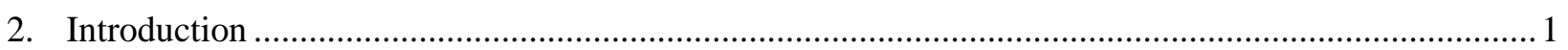

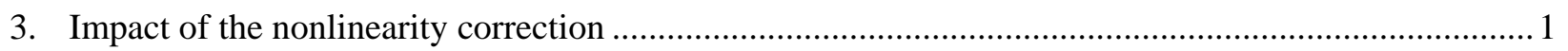

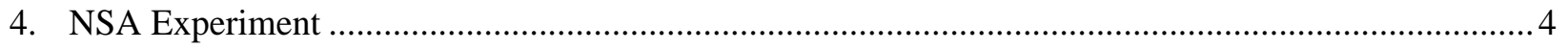

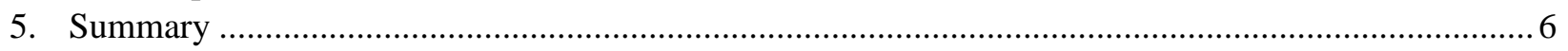

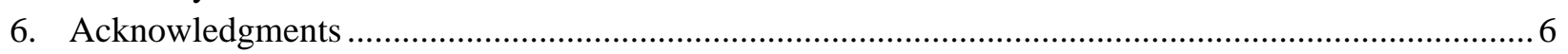

\section{Figures}

1 Time-series of brightness temperature at $900 \mathrm{~cm}^{-1}$ observed by the AERI

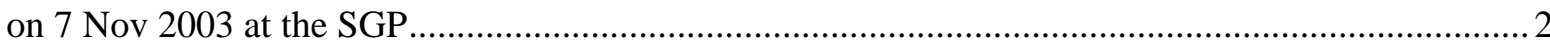

2 Examples of the spectral radiance errors associated with not applying the nonlinearity correction for various sky conditions...................................................................... 3

3 Time-height cross sections of water vapor mixing ratio (left) and temperature (right) retrieved from the AERI on 7 Nov 2003 (upper figures)...................................................... 4

4 The difference between the observed radiance for two AERI systems

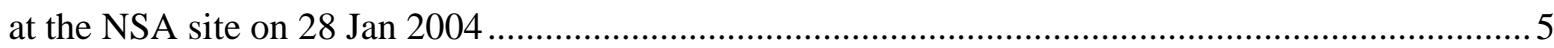




\section{Abstract}

Mercury Cadmium Telluride (MCT) detectors provide excellent sensitivity to infrared radiation and are used in passive infrared remote sensors such as the Atmospheric Emitted Radiance Interferometer (AERI). However, MCT detectors have a nonlinear response and thus this nonlinearity must be characterized and corrected to provide accurate infrared radiance observations. This paper discusses the significance of the nonlinearity correction applied to AERI data and its impacts on the parameters retrieved from the AERI spectra. It also evaluates the accuracy of the scheme used to determine the nonlinearity of the MCT detectors used in the Atmospheric Radiation Measurement (ARM) Program’s AERIs.

\section{Introduction}

The Atmospheric Emitted Radiance Interferometer (AERI) instrument provides accurate, high spectral resolution, ground-based infrared radiance observations for the U.S. Department of Energy (DOE) Atmospheric Radiation Measurement (ARM) Program (Knuteson et al. 2004). AERIs have been deployed to many regions of the world as part of ARM and other programs. The AERI is built around a commercially available interferometer, and uses two highly characterized blackbody sources to provide the radiometric calibration. Careful attention to calibration has resulted in a radiometric uncertainty that is less than $1 \%$ of the ambient radiance (3-sigma) (Knuteson et al. 2004), which was the specified accuracy required by the ARM Program.

One component of the AERI's calibration is accounting for the nonlinearity of the MCT detector that provides sensitivity to radiance from 5-19 $\mu \mathrm{m}$ (or from 5-25 $\mu \mathrm{m}$ in the extendedrange systems deployed in the Arctic). The nonlinear response in the MCT detectors used in the AERI have been investigated extensively (Revercomb 1994; Revercomb et al. 1998), and a correction has been formulated using a physical model of the nonlinear response in the interferogram domain. Analysis of the various terms demonstrated that only the quadratic term was needed; accounting for the higher-order terms was not necessary to maintain the radiometric uncertainty to the specified accuracy of better than $1 \%$ ambient radiance (Knuteson et al. 2004). Views of hot, ambient, and liquid nitrogen cooled blackbodies are collected over the process of several hours, and out-of-band data are used to determine the magnitude of the quadratic correction factor. This procedure characterizes the non-linearity of the detector to within $10 \%$, which implies an uncertainty associated with the nonlinearity of the detector (after it has been corrected) of less than $0.2 \%$ of the ambient radiance (Knuteson et al. 2004).

\section{Impact of the nonlinearity correction}

To gain an appreciation of the impact of the nonlinearity correction on the radiance data, AERI data collected at the ARM Southern Great Plains (SGP) site on 7 Nov 2003 were reprocessed without the correction, and these data were compared to the nominally processed data. This day has four distinct sky condition periods that are easily identifiable in the observed sky brightness temperature at $900 \mathrm{~cm}^{-1}$ as measured by the AERI (Figure 1): (1) clear sky from 0000-0800 Universal Time Coordinates (UTC), (2) a mid-level cloud at approximately $6 \mathrm{~km}$ (determined by a lidar) from 0800-1430 UTC, (3) another clear sky period until 1830 UTC, and 
(4) a low stratus cloud at $2 \mathrm{~km}$ for the rest of the day. The difference in the observed sky brightness temperature is between the nominally processed data and the data that were processed without the nonlinearity correction shown in the middle panel of Figure 1 . The brightness temperature (or equivalently, the radiance) difference is a function of the scene temperature; for colder scenes the error associated with not applying a nonlinearity correction becomes larger. Therefore, fewer errors exist in the uncorrected radiance associated with the cloudy scenes, but significant errors are (approaching $0.5 \%$ of the ambient radiance, as shown in the bottom panel of Figure 1) associated with the clear sky scenes at this wavelength.
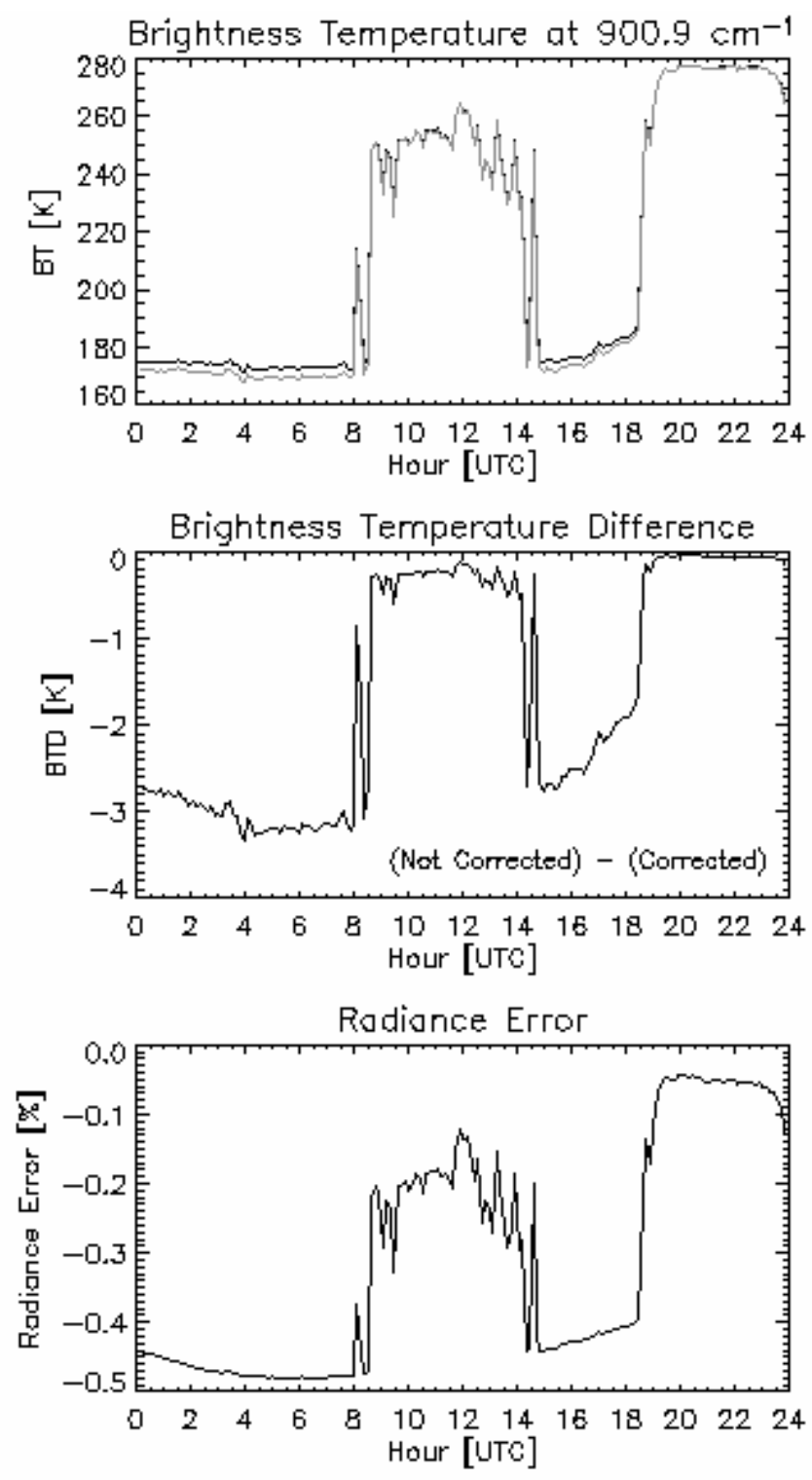

Figure 1. Time-series of brightness temperature at $900 \mathrm{~cm}^{-1}$ observed by the AERI on 7 Nov 2003 at the SGP site with (gray) and without (black) the nonlinearity correction applied (top). Also shown are the brightness temperature difference (middle panel) and the radiance error with respect to the ambient radiance associated with not applying the nonlinearity correction (bottom). Note that the specified accuracy is $1 \%$ of the ambient radiance; therefore, not applying this correction uses up nearly half of total error budget. 
Because the impact of the nonlinearity correction is scene-temperature dependent, the correction has spectral structure. Figure 2 shows the difference between the nominally processed versus uncorrected data for three spectra chosen from the different scenes on 7 Nov 2003: low cloud at 2204 UTC (light gray), mid-level cloud at 1105 UTC (black), and clear sky at 0502 UTC (medium gray). The residuals are shown as both in terms of radiance units $\left[\mathrm{RU}, \mathrm{mW} /\left(\mathrm{m}^{2}\right.\right.$ ster $\mathrm{cm}^{-1}$ )] in the middle panel and as a percent difference relative to the ambient radiance (bottom panel). For the two cloudy scenes, the error in radiance relative to the ambient radiance that results when the nonlinearity correction is not applied is smaller than $0.3 \%$, but for the clear sky case, the errors are $0.75 \%$ across the infrared window. Therefore, uncertainties associated with the specification of the nonlinearity correction are only important for clear sky AERI applications; cloud microphysical property retrieval algorithms that use AERI data (e.g., Turner 2004; DeSlover et al. 1999) are unaffected by this uncertainty.
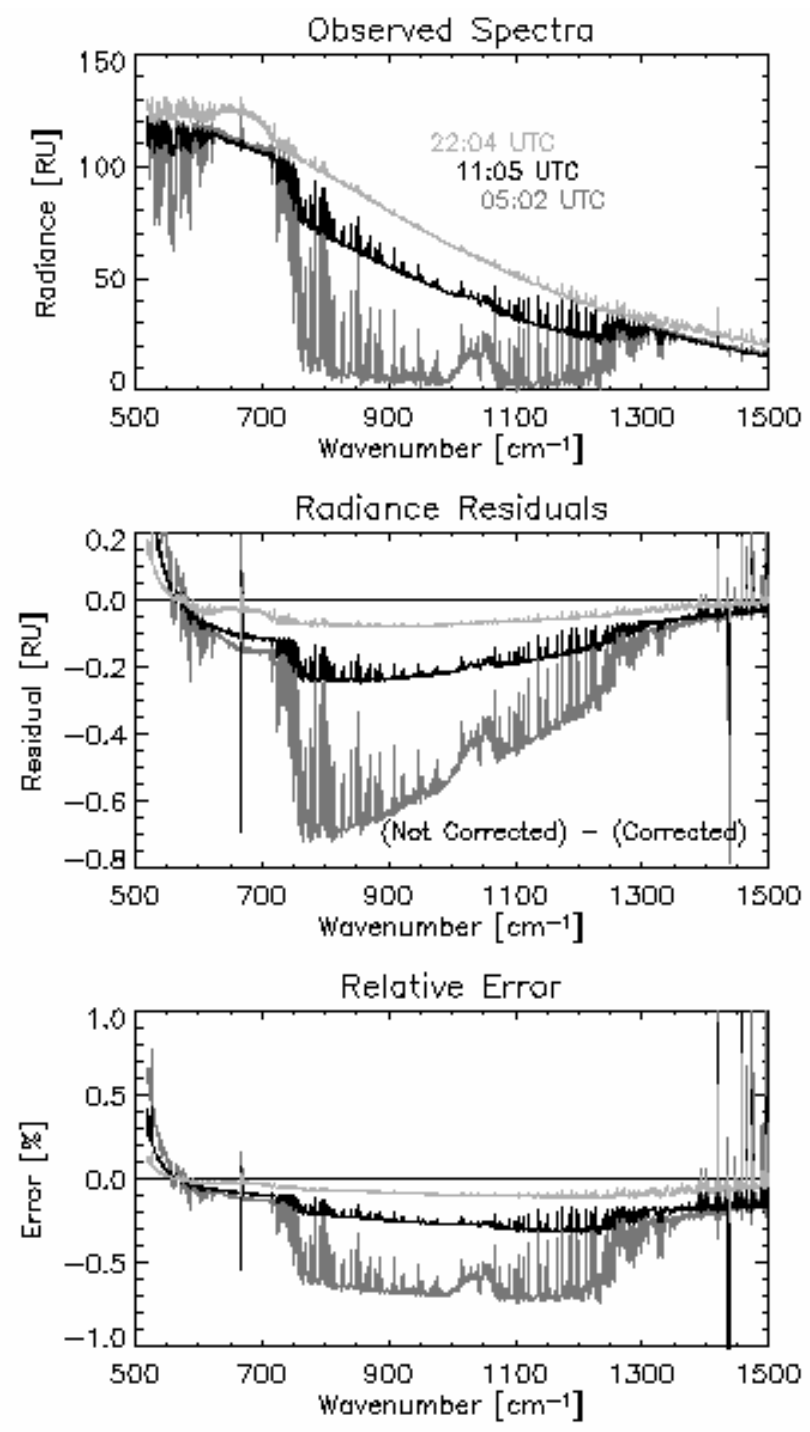

Figure 2. Examples of the spectral radiance errors associated with not applying the nonlinearity correction for various sky conditions. See text for details. 
The ARM Program has two important clear-sky applications of AERI data. The first is the QME AERI LBLRTM (henceforth called the QME), which compares the downwelling radiance observed by the AERI with calculations by the line-by-line radiative transfer model LBLRTM (Turner et al. 2004). The QME's objective is three-pronged: (1) to evaluate the radiance observations from the AERI, (2) to evaluate and improve the state-of-the-atmosphere observations (primarily water vapor), and (3) to evaluate and improve the LBLRTM (and in particular the water vapor continuum absorption model). Since uncertainties in the nonlinearity correction affect clear sky radiances in the window the most, the QME is highly sensitive to any errors in the specification of this correction. All work performed under the auspices of this QME have assumed that the nonlinearity correction is adequately specified.

The other important ARM clear sky AERI application is the retrieval of temperature and water vapor profiles from the AERI radiance data (Feltz et al. 2003). To investigate the impact, the temperature/water vapor retrieval algorithm was run on both the corrected and uncorrected AERI data. Time-height cross sections of the data, along with time-height cross sections of the differences, are shown in Figure 3. Note that the cloudy regions have been removed from this analysis. The differences in both the temperature and water vapor retrievals show vertical structure, but the maximum error that occurs by not applying the nonlinearity correction is $0.15 \mathrm{~K}$ and $0.15 \mathrm{~g} / \mathrm{kg}$, respectively. Taken together, this amounts to an approximate error of $3 \%$ in relative humidity. The errors in these retrieved fields are small because the spectral elements used in the retrieval algorithm, which have weighting functions that peak at or near the surface, are relatively close to the ambient temperature.
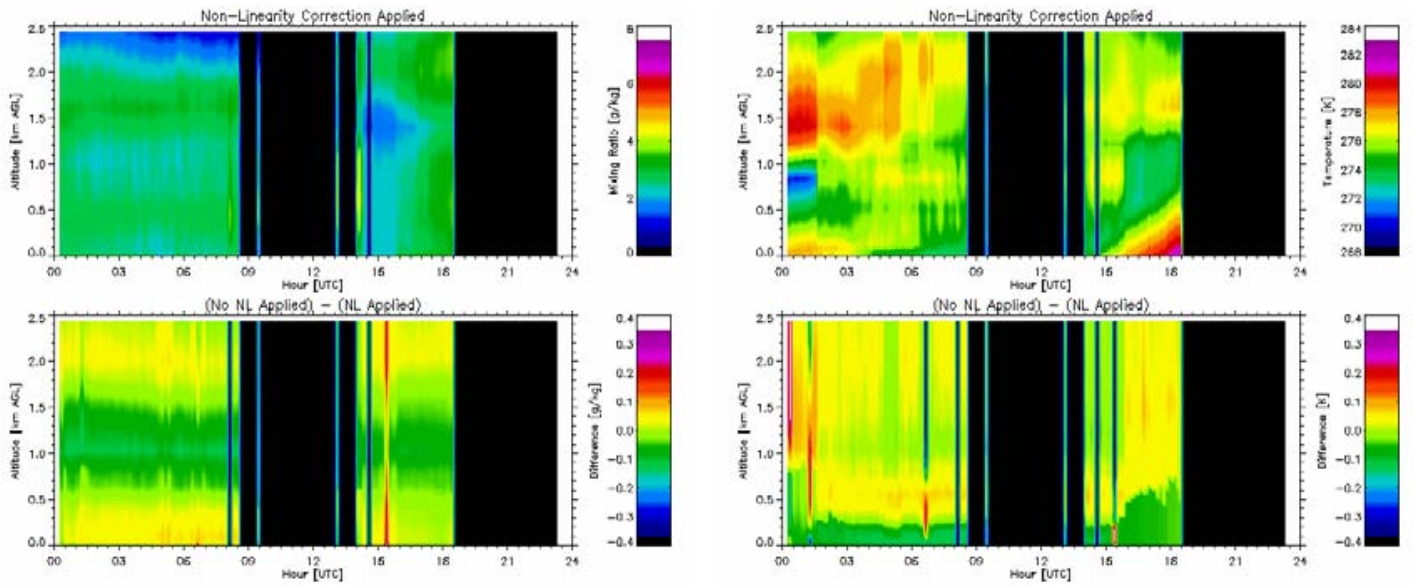

Figure 3. Time-height cross sections of water vapor mixing ratio (left) and temperature (right) retrieved from the AERI on 7 Nov 2003 (upper figures). The lower figures display the time-height differences in the retrieved profiles if the nonlinearity correction was not applied to the AERI data.

\section{NSA Experiment}

The discussion above has demonstrated that the main application that could be affected by an inadequate nonlinearity correction is the QME. QME residuals at both the SGP site and in the Arctic (at both the ARM North Slope of Alaska [NSA] site and during the Surface Heat Budget of the Arctic [SHEBA] experiment) show a significant observed minus calculated residual for 
clear sky, low water vapor conditions (Turner et al. 2004; Turner 2003). Turner (2003) studied various possible mechanisms for this small, relatively gray residual (1 RU at $900 \mathrm{~cm}^{-1}$ ), but was unable to determine its source. One possible explanation is that the nonlinearity correction for the AERIs was inadequately determined.

The out-of-band analysis outlined in Knuteson et al. (2004), which is performed for each AERI before it is deployed to the field, has suggested that the AERI-ER systems (which are deployed to the Arctic) require no nonlinearity correction. The nonlinear response of the detector is a function of signal amplitude, thus larger signals (such as from warmer scenes) will suffer the most from an inadequately determined correction. The hot blackbody's temperature is maintained nominally at $333 \mathrm{~K}\left(60^{\circ} \mathrm{C}\right)$, and thus the warmest scene observed by the AERI is the view of the hot blackbody. Therefore, reducing the temperature of the hot blackbody should provide a robust test to the adequacy of the nonlinearity correction.

In January 2004, a second extended-range AERI (AERI-ER) system was deployed next to the operational AERI-ER system at the NSA site. Data were collected with both systems running in their nominal configurations (i.e., both used the same hot blackbody temperature); these data verified that both instruments agreed with each other to within measurement uncertainties. Then, the hot blackbody temperature of the second system was set to $303 \mathrm{~K}$. A comparison of clear sky data from both systems (Figure 4) demonstrated that again the two instruments agreed to within the measurement uncertainties. Therefore, we conclude that the nonlinearity corrections applied to these two systems (and by inference the out-of-band procedure used to determine these corrections) are correct. This leaves the source of the AERI - LBLRTM bias observed in clear dry conditions to be unresolved at this time.
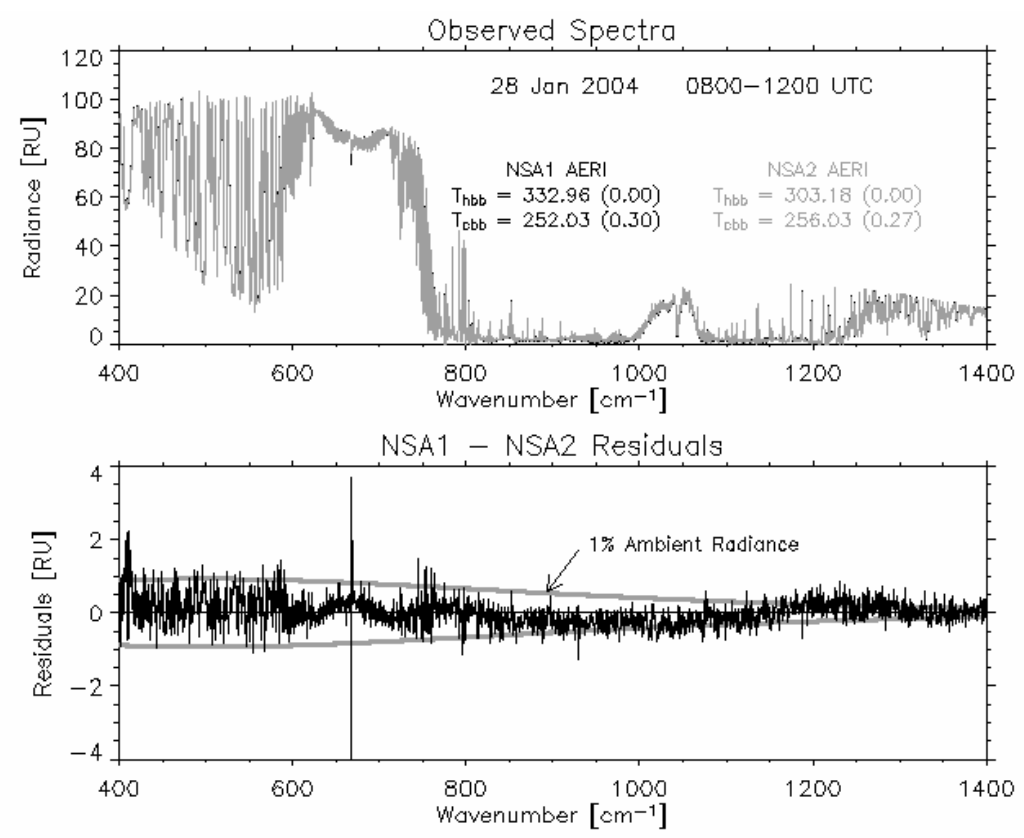

Figure 4. The difference between the observed radiance for two AERI systems at the NSA site is shown for 28 Jan 2004, where the hot blackbody temperatures on each system are significantly different. The difference is within $1 \%$ of the ambient radiance; i.e., within the AERI specifications. 


\section{Summary}

The nonlinearity of the MCT detector, if not corrected for or inadequately corrected for, can lead to significant errors in the 8-13 $\mu \mathrm{m}$ window radiance data observed by the AERI in clear sky conditions. These errors are significant for evaluating clear sky radiative transfer algorithms, such as the LBLRTM, with AERI data, as well as studies involving aerosol or other optically thin layers using AERI data. The nonlinearity correction can be determined using an out-of-band procedure that has been recently published (Knuteson et al. 2004). A side-by-side comparison of two AERI systems with markedly different hot blackbody temperatures demonstrated good agreement, suggesting that the nonlinearity corrections for the two systems were correctly determined by the out-of-band procedure.

\section{Acknowledgments}

We would like to thank Denny Hackel for reprocessing the AERI data without the nonlinearity correction and Tim Wagner for running the temperature / water vapor retrieval algorithm on this data. Walter Bower, NSA site operations, was extremely helpful in getting the second AERI system installed and operating at the NSA site. This work was performed as part of the DOE ARM Program.

\section{References}

DeSlover, D.H., W.L. Smith, P.K. Piironen, and E.W. Eloranta, 1999: A methodology for measuring cirrus cloud visible-to-infrared spectral optical depth ratios. J. Atmos. Oceanic Technol, 16, 251-262.

Feltz, W. F., H. B. Howell, R. O. Knuteson, H. M. Woolf, and H E. Revercomb, 2003: Near Continuous Profiling of Temperature, Moisture, and Atmospheric Stability using the Atmospheric Emitted Radiance Interferometer (AERI). J. Appl. Meteor., 42, 584-597.

Knuteson, R.O., H.E. Revercomb, F.A. Best, N.C. Ciganovich, R.G. Dedecker, T.P. Dirkx, S.C. Ellington, W.F. Feltz, R.K. Garcia, H.B. Howell, W.L. Smith, J.F. Short, and D.C. Tobin, 2004: Atmospheric Emitted Radiance Interferometer (AERI) Part II: Instrument Performance. J. Atmos. Oceanic Technol., in press.

Revercomb, H.E., 1994: Techniques for avoiding phase and non-linearity errors in radiometric calibration: A review of the experience with the airborne HIS and ground-based AERI. Proceedings of the $5^{\text {th }}$ International Workshop on Atmospheric Science from Space using FTS, pp 353-378, Tokyo, Japan.

Revercomb, H.E., and coauthors, 1998: Recent results from the scanning high-resolution interferometer sounder (S-HIS) aircraft instrument. Proceedings of the $8^{\text {th }}$ International Workshop on Atmospheric Science from Space using FTS, Toulouse, France. 
Turner, D.D., 2003: Microphysical properties of single and mixed-phase Arctic clouds derived from ground-based AERI observations. Ph.D. Dissertation, University of Wisconsin - Madison, Madison, Wisconsin, 167 pp. Available from

http://www.ssec.wisc.edu/library/turnerdissertation.pdf.

Turner, D.D., 2004: Arctic mixed-phase cloud properties from AERI-lidar observations:

Algorithm and results from SHEBA. J. Appl. Meteor., submitted

Turner, D.D., D.C. Tobin, S.A. Clough, P.D. Brown, R.G. Ellingson, M.J. Mlawer, R.O.

Knuteson, H.E. Revercomb, T.R. Shippert, and W.L. Smith., 2004: The QME AERI LBLRTM: A closure experiment for downwelling high spectral resolution infrared radiance. J. Atmos. Sci., in press. 